\title{
Skills Management: Successful Communication in Business Negotiations
}

\author{
Dr. Claudius Mandel \\ FOM - Hochschule für Oekonomie und Management \\ University of Cologne, Professional Center \\ Germany
}

\begin{abstract}
Negotiations represent a formative element in professional life. The development and continuous expansion of practical negotiation skills is therefore an important task within the framework of individual competence development. From an interdisciplinary perspective, this article therefore focuses on the central elements of professional negotiation: analysis, strategies and tools in the context of communication. A good negotiation result is regularly characterized by the fact that the assertiveness of one's own interests goes hand in hand with empathy for the interests of the negotiating partner. In an interplay of integrative and distributive negotiation, value is jointly created and individually claimed. The more a negotiation result is based on objective decision-making principles and at the same time unfolds the power of a creative solution, the greater the chance of an agreement between the negotiating parties.
\end{abstract}

Keywords: negotiation, communication, skills, skills management, competency management, salary negotiation, success

\section{Relevance of negotiating competence}

Negotiating situations represent a formative element of human experiential reality: In business, politics and law, reconciliations of interests in the form of negotiated solutions are regularly sought. At the economic level, negotiations are constitutive for any form of business relationship between service exchanging companies. However, hierarchical changes in the working world also mean that project-specific personnel and material resources can only be recruited and/or released if the expectations of all project participants have been communicated in advance, coordinated and the relevant target positions negotiated and fixed. Negotiations also play a prominent role within the company. This applies both to established employees of a company and to potential employees who are in an (advanced) application process. In all these negotiation contexts, people meet in a wide variety of exchange relationships. They compete for resources and want to realize their interests. The diversity of these negotiation situations occurring in the realities of individuals and groups of people indicates the relevance of dealing with the topic. Even experienced negotiation practitioners sometimes stubbornly hold the view that being able to negotiate effectively is exclusively a question of talent, that one cannot learn this ergo at all - or that intellect and practical experience alone are sufficient to achieve good negotiation results (cf. Rosner/Winheller 2012, p. 76 f.). However, this assessment is countered by empirical findings that focus on the effect of good quality negotiation training on individual negotiation skills and negotiation outcomes: With regard to the factor of negotiation experience, the studies come to the conclusion that experienced negotiators (2-3 years) achieve significantly better negotiation results than inexperienced negotiators. At the same time, it can be seen that additional experience only generates further advantages for already experienced negotiators under certain conditions: Participation in effective negotiation training is therefore necessary. This is because the previous negotiation practice can be selfcritically reflected against the background of relevant negotiation research results (cf. Voeth/Herbst 2009, p. 62 f.; Thompson 2009, p. 9). On the other hand, by completing suitable negotiation workshops, new negotiators can neutralise the critical success factor of negotiation experience compared to experienced negotiators without taking advantage of negotiation training offers (cf. Herbst/Schwarz 2011, p. 163 ff.). Overall, the effectiveness of various forms of negotiation training can be regarded as proven (cf. Coleman/Lim 2001; Loewenstein et al. 2003; Nadler et al. 2003).

These insights reveal what becomes clear on closer examination of the subject matter of the present study: Professional negotiation is a highly complex challenge, the successful mastering of which requires intensive engagement with relevant research findings, training of practical negotiation skills, continuous generation of negotiation experience and constant critical reflection on one's own negotiation practice (cf. Haft 2000, p. $1 \mathrm{f}$.). This insight is also reflected in the fact that negotiations have now been the subject of research for four decades in various disciplines, primarily economics, political science, mathematics (game theory) and communication psychology (cf. Moffit/Bordone 2005; Däubler 2003; Voeth/Herbst 2009). The undisputed basic literature on the subject, on which the following remarks are based, is the Havard concept Getting to Yes, first published in 1981. 
In it, the authors Fisher, Ury and Patton, directors of the renowned Harvard Negotiation Project, propagate the method of objective negotiation. Following this tradition, negotiation can be defined "as joint work on the realization of interests" (Bühring-Uhle et al. 2017, p. 4).

\section{Professional negotiation}

The need to develop an objective and, at the same time, interest-oriented negotiation concept arises from the recognition that intuitive procedures have clear disadvantages: Intuitive negotiation follows the typical bazaar ritual and assumes that negotiations are always to be regarded as zero-sum games - for example, a ten percent salary increase on the employee side is understood as a loss of resources of exactly the same order of magnitude on the employer side. Such self-interested position thinking inevitably turns negotiation into a distribution battle. Thus, the opportunity is missed to create common added value through cooperation and to work out (creative) options for agreement in exchange with the negotiating partner to the mutual advantage. The Harvard concept illustrates the advantages of focusing not on positions but on the needs, wishes, feelings and fears of the negotiators behind the positions, i.e. their interests, using the following example:

"All too often, however, the negotiating partners are like the two proverbial sisters who argued over an orange. After finally agreeing to halve the fruit, the first took her half, ate the flesh and threw away the bowl; the other threw away the inside instead and used the bowl because she only wanted to bake a cake. ... Far too many negotiations end with half the orange for each side instead of the whole fruit for one and the whole bowl for the other." (Fisher et al. 2004, p. 92)

In order to be able to approach decision-making between different negotiating parties in a well-thought-out and structured manner, it is worthwhile in the run-up to a negotiation meeting to theoretically grasp the forthcoming decision-making process on the basis of relevant parameters. This provides a framework that makes it possible to look at the parameters under whose influence the future decision will be made. This allows a targeted influence to be exerted on the decision making process. The central components of this framework are presented in the following section.

\subsection{Analysis}

The process of decision-making in negotiation situations can be described analytically using the parameters shown in Figure 1 (cf. Bühring-Uhle et al. 2017, p. 25 ff.).

Fig. 1: Analysis framework of a negotiation

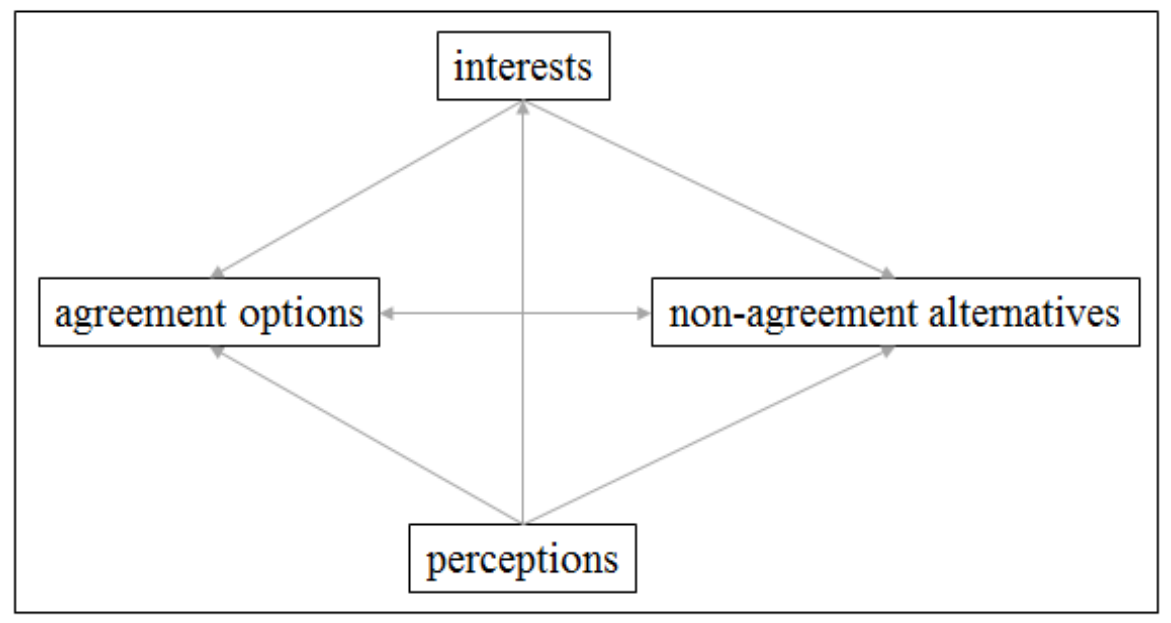

Source: According to Bühring-Uhle et al. 2017, p. 26, p. 32, p. 39.

In each negotiation, the participants are faced with the task of either agreeing on one of the possible solutions available to them, or not reaching a conclusion. If the parties are willing to reach an agreement, they choose between different options. If no agreement is reached, the negotiating parties fall back on their respective, ideally existing non-agreement alternatives. Options for agreement and alternatives to non-agreement are thus the subject of every negotiation decision. The specific interests of the negotiating parties regularly serve as a yardstick for assessing this decision, whereby the basis of the decision is always constituted by the negotiating parties' perception of themselves and others with regard to the other parameters. Options for reaching an agreement are characterized by the fact that they represent a mutually beneficial result that has been worked out so concretely that the agreement can be directly implemented. 
It must be ensured that the individual aspects of an agreement option are subjected to objective assessment criteria, for example a market value, an expert opinion or a recognized standard. All negotiating parties are most likely to submit to a fair solution based on neutral standards. The more creative force inherent in the settlement options, as in the orange example cited, the greater the chance of agreement between the negotiating parties (cf. Bühring-Uhle et al. 2017, p. 12 ff., p. 26 ff.; Fisher et al. 2004, p. 34 ff.).

In the concrete case of a salary negotiation, it is worthwhile for both negotiating parties to extend the narrow framework of exclusively fixed monetary aspects to the design of remuneration arrangements consisting of several building blocks. The following aspects can, for example, become components of settlement options in salary negotiations:

- fixed salary

- variable salary / bonus

- number of vacation days

- company car

- company bike

- public transport ticket

- training opportunities / budget

- career opportunities

- job title

- laptop \& smartphone

- contract: fixed-term versus open-ended

- working hours: fixed versus flexible

- home office Opportunities

The work on potential settlement options is thus a central task in the course of preparing the negotiations as well as during the negotiation itself. A systematic approach is recommended, which collects and arranges possible solutions as well as individually evaluates and ranks them. The aim should be to create as many (for oneself) as possible equal agreement options, each of which is characterized by a different design of the sub-components considered in it. On the basis of such preliminary work, a confident appearance in the negotiation discussion can take place on the one hand; on the other hand, such a procedure increases the chances that your negotiating partner will agree to one of the various proposed sets for an agreement.

It is advisable to make certain distinctions when analyzing the interests involved in negotiations. The following questions outline perspectives that can be taken to concretize one's own and others' interests:

- Does the negotiation assess exclusively material interests or do immaterial interests also play an essential role? Is it possible for a negotiating party, in this case the employer, to satisfy an immaterial interest (e.g. the wish for a more honorable sounding job title) of the negotiating partner by means of little or no material effort?

- Do the interests have to be realized at present or is a future satisfaction sufficient? Is it possible for an employee to forego a higher salary when starting a job today if salary increases are agreed and fixed in advance after certain points in time?

- Is the negotiation to be regarded as purely result-fixed or can a procedural view be taken? Is it central, for example, to extract the maximum from the current round of negotiations, or is the interest in a secure, long-term working relationship classified as more relevant?

Dealing with individual interests also inevitably leads to a discussion of the topic of non-integration alternatives, the second central area of responsibility in negotiation management (cf. Fisher et al. 2004, p. 145 ff.; Bühring-Uhle et al. 2017, p. 28 ff., p. 107 ff.). The non-agreement alternative describes the situation of each negotiating party if no negotiated solution is reached. It thus represents a lower limit for each negotiating party. Rationally acting parties do not agree to an agreement option which is below the realization of interests as a result of the choice of a non-agreement alternative. The importance of one's own work on a non-agreement alternative, also known as the best alternative, cannot be overestimated in the context of negotiations. For the more attractive an existing alternative to non-union is, the more bargaining power there is, the more independently the negotiating space can be entered (cf. Craver 1986, p. 72 f.):

- In a company's job interview, the negotiation position of a potential employee is better when alternative offers of contracts ready for signature (ideally of higher value compared to the (opening) offer of the specific company) are available. Even if further (potentially promising) job interviews have already been fixed, the negotiating position improves. 
- For the employer, the negotiating position also improves decisively if he has equivalent alternatives for the filling of a certain position at his disposal, possibly at more favorable overall conditions.

The work on one's own non-agreement alternatives thus becomes an essential component of every negotiation preparation for both negotiating parties. Their value lies first and foremost in being able to leave the negotiation room at any time without any problems and even without an agreement. The non-agreement alternative can take various forms: From the employee's point of view, for example, an agreement can be sought with another partner (acceptance of another job offer) or the employee can become self-employed (founding his own company).

Finally, the subjective perception of the negotiating partners is decisive for the individual and joint work on settlement options, for the party-specific confrontation with non-agreement alternatives and the respective existence of interests. For example, it is useless to refer to the (actual) existence of an alternative, better offer in the context of a job interview if the opposite side doubts the existence of this offer, i.e. subjectively perceives it as not being present. Likewise, the desired effect can be obtained - for instance a subsequent improvement of the offer of the opposite side - also if the submitted alternative offer does not exist in reality, whose existence is accepted by the negotiation partner however as true.

\subsection{Strategies and tools}

Basically, a distinction can be made between integrative and distributive negotiation strategies. Modern negotiation management regularly presents itself as a tense interplay of integrative value creation and distributive value claim, cooperation and competition (cf. Walton/McKersie 1965, p. 11 et seq., p. 126 et seq.): Successful negotiators create cooperation gains in cooperation with their negotiating partners and thus increase the negotiating mass available for distribution. On the other hand, however, they are also anxious to act in such a way that they receive the largest possible share of the profits from cooperation. Integrative and distributive approaches are therefore fundamentally different with regard to the tools used (cf. Pfromm 2016, p. 22 ff.).

\section{Integrative negotiation}

Integrative negotiation means creating value through the joint development of mutually beneficial settlement options (in comparison to the respective non-agreement alternatives) and thus eliminating the supposed limitations of a negotiating mass. This added value can be achieved by finding common interests, but also by exploiting different interests (cf. Fisher et al. 2004, p. 110 ff.).

Imagine a job-related annual meeting in which employer and employee negotiate the employee's future remuneration: The employee demands a ten per cent salary increase; his idea is thus above that of the employer. If the negotiating partners now remain at the level of the exchange of positions, any deviation of a negotiating partner from its initial position will represent a loss for it and a profit will be realized in exactly the same amount as the other negotiating side. This would intuitively turn the negotiation into a zero-sum game (cf. Schelling 1980, p. $83 \mathrm{ff} .$, p. 163). This is inefficient. Effective and efficient integrative negotiation, on the other hand, can be achieved first and foremost by focusing on the common interests of the negotiating partners. This can be achieved to the extent that the negotiating partners ask themselves whether they have a common interest in (long-term) preservation of their business relationship (cf. Rosner/Winheller 2012, p. 128 ff.). The following questions can also be asked: Is there a reference value, a market or company-specific level that both parties can recognize equally? What would the costs be if negotiations were broken off? The focus on common interests usually makes the negotiation more fluent and atmospheric. And even if the employer and employee do not agree on the continuation of the employment relationship in the example outlined and the discussion threatens to escalate against the background of a possibly necessary determination of certain severance payments, there is still the possibility of exploiting similarities, if not in content, then in procedure. Here, for example, one common ground may be to avoid a court dispute and instead choose an alternative conciliation procedure, such as mediation.

Integrative negotiation between employer and employee can also create value through the simultaneous fusion of different interests. This may be outlined using the following three tools:

- Exploiting different time preferences: The employer may even be willing to pay more than the employee demands if he has to do so at a later date. If the employee is now able to do without a ten percent higher salary today and three rounds of salary increases of five percent each are agreed and fixed in the future, spread over the next twenty months or so, then the two parties will find each other by merging different interests.

- Exploiting different forecasts: The employer assumes that the employee's key performance indicators will fall significantly in the coming financial year due to the economic situation or individual circumstances. The employee assumes the opposite. If employers and employees agree on a salary model consisting of a fixed (e.g. two percent more 
than before) and a relevant variable (e.g. up to fifteen percent on top) salary component, both parties will benefit from the negotiation.

- Utilization of different value concepts: While a moderate increase in wage costs is important for the employer, other components may be decisive for the employee's well-being in addition to the salary: for example, the possibility of working in the home office on certain days, more flexible working hours in principle or being able to take more vacation days a year. By putting together a remuneration package that consists of different modules (see list above) and corresponds to the different interests of the negotiating partners, joint value can be generated.

\section{Distributive negotiation}

Distributive negotiation aims at claiming individual value, ideally on the basis of an increased negotiating mass through integrative negotiation. Other tools are used for this purpose than in integrative mode: information is only selectively communicated here. Sometimes manipulation attempts are also made. Specifically, the following three tools are available in the context of distributive negotiation:

- Perception anchor: The value stress phase can be shaped by the throwing of an anchor and the psychological anchor effect it generates on the negotiating partner. What is meant by this is that by setting a starting point for the first time, for example by naming a certain number in negotiations, the area of agreement of the negotiation is predetermined. Numerous empirical studies have shown that negotiating partners regularly take the number mentioned among them as the starting point for their discussion and that the ensuing dispute revolves only around the amount of a minor modification. Extensive knowledge of the market environment can objectively legitimize the anchor thrown, but the anchor effect typically occurs even if the anchor was determined by chance, i.e. it has no greater legitimacy objectively in relation to alternative settings (cf. Ariely 2008, p. 25 ff., Kahnemann 2011, p. 119 ff.). The anchor effect also makes use of another psychological effect: If, in the end, the outcome of the negotiations is numerically (slightly) lower than the initially set anchor, the opposing side regards this as a success regardless of whether the anchor represented a realistic opening demand or not (cf. Pfromm 2016, p. 27).

- Manipulation with concessions: In every negotiation, there are phases in which an attempt is made to reach an agreement through an exchange of concessions. In this context, it is possible to enhance the significance of one's own concessions or even to invent one's own concessions. This procedure has a manipulative deceptive character and is based on the reciprocity requirement of the negotiating partner. To report untruthfully on the extent or existence of a concession pursues the goal of obtaining a concession of "equal magnitude" from the other party and of a genuine nature (cf. Bühring-Uhle et al. 2017, p. 49 f., p. 81 ff.). In the context of a salary negotiation between employer and employee, the employee could, for example, by referring to a (supposed) large number of overtime hours worked in order to successfully complete the last project, persuade the employer to make a correspondingly high salary adjustment. The employer, on the other hand, could increase the dimension of previous accommodations on his part in order to melt off the demands of the other side.

- Cheap satisfaction of interests: Assuming that the employee has actually made a significant contribution to the success of the company by constantly working overtime, the employer could try to satisfy the justified demand for relevant salary increases cheaply: Perhaps the employee agrees to a one-off payment, an incentive trip or even just an internal symbolic highlighting, for example as employee of the month (cf. Bühring-Uhle et al. 2017, p. 83 f.).

In principle, all tools of distributive negotiation bear the danger of a negotiation escalation: set anchors can be countered by an extreme number of the opposite side, manipulations with concessions can be formulated exaggerated and thus exposed, and even the attempt at a cheap satisfaction of interests can not only not catch, but also provoke considerable displeasure in the opposite side.

\subsection{Communication}

Just as integrative and distributive negotiation is implemented - the importance of communication at the negotiating table is regularly given special weight. Here, too, specific tools can be determined:

- Nonverbal communication: The significance of nonverbal communication in the context of negotiations is decisive quantitatively and qualitatively (cf. Craver 1986, p. 19 ff.). Even more important than the interpretation of certain gestures of the opposite side - for example the perception of an upper body bent forwards/backwards as a signal of interest/disinterest (cf. Bürger/Parzinger 1998, p. $147 \mathrm{ff}$.) - is to constructively shape the atmosphere at the negotiating table itself. For this purpose, the empirically proven effectiveness of the technique of behavioral mirroring can be used: By aligning one's own posture with that of one's counterpart, sympathy can be generated on the one hand and tense conversational constellations can be resolved on the other (cf. Dabbs 1969, p. 337 f.).

- Active listening: This means to establish a connection to the other through the use of gestures (body posture turned towards, eye contact) and verbal utterances. In order to be able to make the negotiating partner an offer that is acceptable to him, it is first necessary to understand what moves and interests the other before it is possible to talk 
about concrete subjects for negotiation and possible options for agreement. Active listening has in mind that the assumptions regarding the interests of the other side can also be wrong and therefore looks for clues for any necessary corrections (cf. Bühring-Uhle et al. 2017, p. 128 ff.). Active listening can also be practiced through the technique of paraphrasing, i.e. the reproduction of the statement of the negotiating partner (cf. Folberg et al. 2005, p. 101); the latter then expresses the interest and attention in what has been presented and at the same time obtains a request for confirmation of (correct) reproduction. In this respect, paraphrasing makes it possible to formulate small intermediate conclusions on the basis of which progress can then be made.

- Open and closed questions: Different question techniques help to structure the negotiation process in a concrete way.

- Open questions should be used to open up the negotiation space at the beginning of the conversation and to explore the interests of the other person: "What is important to you for the future of our business relationship?" or: "How would you be satisfied?"

- Closed questions, on the other hand, serve to give precision to the information to be obtained or to directly confirm or deny a certain assumption: If, for example, the remuneration philosophy of a company includes a company car as standard, then the potential employee can quickly verify this for his case as well. This information can be obtained with precision, for example, by specifically inquiring about the type of vehicle.

- Ego-statements: While one dives into the world of thoughts and feelings of the negotiating partner through active listening and application of various question techniques, it is just as central to communicate one's own interests, preferences, values and non-agreement alternatives - not least because the negotiating partner must also learn something about his counterpart in order to be able to think about value-adding agreement options on this basis. The formulation of such messages is also advisable when the negotiating partner's assessments are to be put into perspective or corrected (cf. Schulz von Thun 2010, p. 79 ff.) - example: "I find the current negotiating atmosphere very tense and unproductive. I need a short break to get back together." This avoids the danger of making a direct accusation against the other person - for example in the form: "With their aggressive rhetoric they destroy any positive negotiating atmosphere."

- Aggressiveness: Personal attacks and intimidation attempts of verbal form are also usual within the framework of distributive negotiation phases - for example becoming loud, (produced) rage outbreaks, degradations of the authority of the opposite side by references to lacking experience, sex or age. For dealing with such aggressive behaviour of different colour it is recommended to resist temptations of a counterattack or an escape movement - if one does not practice it oneself. Instead, it is advisable to remain unperturbed and insist on continuing the negotiation in a factual manner (cf. Fisher et al. 2004, p. 161 f.). Alternatively, one can also offensively address the intended mechanism of action of the opposing side and thereby raise its legitimacy to the topic: "Name the game" (Ury 1993, p. 39).

- Communication square: Apart from the specific communication techniques outlined above, it is worth considering the four-level model according to Schulz von Thun (2010, p. 25 ff.) from a psychological perspective. This provides a general framework for the training of self-perception and external perception as well as for the communicative control of a negotiation. The model distinguishes between the four levels of factual content, self-revelation, relationship and appeal. Each negotiating partner should be clear about how his communication can be perceived on the different levels by the other side: If, for example, a negotiating party in a negotiation refers at the beginning to having a follow-up appointment in one hour, then this statement at the factual level first contains information about the time budget (one hour) which this party has available for the negotiation. At the self-revelation level, the party signals, among other things, that it must meet various (important) deadlines and that it has carefully considered in advance how much time it would like to devote to this negotiation. However, the statement does not only reveal something about this negotiation participant himself (self-revelation), but also about the relationship to the other side. The relation is rather business, clarified, perhaps also coined by certain super-/subordination elements. And finally an appeal is connected with the statement: One side of the negotiation makes it clear that it wants to get to the point quickly during the negotiation (cf. Bühring-Uhle et al. 2017, p. 127).

\section{Conclusion}

In the economic context, negotiations are omnipresent, also within the company. The development and advancement of practical negotiation skills therefore proves to be elementary: in the context of preparing for negotiations, it is worthwhile to develop a wide range of settlement options that take into account all the common interests and reconcile various concerns. It is also advisable to work on one's own non-agreement alternatives in the run-up to the negotiations. This creates an effective tool with which the largest part of a cooperation profit can regularly be secured. Against the background of an overriding choice of strategy, the focus at the negotiating table itself is on the use of adequate tools. The most important possibility to structure and control the negotiation at the table is communication. If you want to make progress in negotiations in general and in salary negotiations in particular, you must first of all optimize your own communication skills. On this basis, strategic considerations can be implemented effectively and efficiently. 


\section{List of References}

Ariely, D.: Predictably irrational: The hidden forces that shape our decisions, Oakland: Berret-Koehler, 2008.

Bühring-Uhle, C./Eidenmüller, H./Nelle, A.: Verhandlungsmanagement, 2. edition, München: Verlag C.H.Beck, 2017.

Bürger, B./Parzinger, D.: Körpersprache, Augsburg: Weltbild, 1998.

Coleman, P./Lim, Y. Y. J.: A systematic approach to evaluating the effects of collaborative negotiation training on individuals and groups, in: Negotiation Journal, 17 (2001), Nr. 4, p. 363-292.

Craver, C.: Effective legal negotiation and settlement, Charlottesville: Michie 1986.

Dabbs, J. M.: Similarity of gestures and interpersonal influence, in: Proceedings of the 77th convention of the American Psychological Association, 1969, Nr. 4, p. 337-338.

Däubler, W.: Verhandeln und gestalten. Der Kern der neuen Schlüsselqualifikationen, München: C.H.Beck, 2003.

Fisher, R./Ury, W./Patton, B. M.: Das Harvard-Konzept, 22. edition, Frankfurt/New York: Campus Verlag, 2004.

Folberg, J./Golann, D./Kloppenberg, L./Stipanowich, T.: Resolving Dispute: Theory, practice, and law, New York: Aspen Publishers, 2005.

Haft, F.: Verhandlung und Mediation, 2. edition, München: Verlag C.H.Beck, 2000.

Herbst, U./Schwarz, S.: How valid is negotiation research based on student sample groups, in: Negotiation Journal, 27 (2011), Nr. 2, p. 147-170.

Kahnemann, D.: Thinking, fast and slow, New York: Penguin, 2011.

Loewenstein, J./Thompson, L./Gentner, D.: Analogical Learning in negotiation teams: Comparing cases promotes learning and transfer, in: Academy of Management Learning and Education, 2 (2003), Nr. 2, p. 119-127.

Moffit, M./Bordone, R. (ed.): The handbook of dispute resolution, San Francisco: Jossey-Bass, 2005.

Nadler, J./Thompson, L./van Boven, L.: Learning negotiation skills: Four models of knowledge creation and transfer, in: Management Science, 49 (2003), Nr. 4, p. 529-540.

Pfromm, R. A.: Effektiver verhandeln, Bonn: Deutscher Anwaltverlag, 2016.

Rosner, S./Winheller, A.: Mediation und Verhandlungsführung, München: Rainer Hampp Verlag, 2012.

Schelling, T.: The strategy of conflict, Cambridge: Harvard University Press, 1980.

Schulz von Thun, F.: Miteinander reden, Band 1: Störungen und Klärungen: Allgemeine Psychologie der Kommunikation, 48. edition, Reinbek: Rowohlt, 2010.

Thompson, L.: The mind and heart of the negotiator, 4. edition, Upper Saddle River: Prentice Hall, 2009.

Ury, W.: Getting past no: Negotiating your way from confrontation to cooperation, New York: Bantam Books, 1993.

Voeth, M./Herbst, U.: Verhandlungsmanagement, Stuttgart: Schäffer-Poeschel, 2009.

Walton, R./McKersie, R.: A behavioral theory of labor negotiations, New York: Cornell University Press, 1965. 